\section{Resolución clínica en la atención primaria de salud}

\section{Clinical decissions in primary health care}

\section{Sr. Editor:}

La atención primaria de salud (APS) constituye la primera fase del proceso de asistencia sanitaria. En nuestro país ha sido encargada al Médico General (MG), quien, recordando la figura del "médico de cabecera", tan antigua como la propia Medicina, debe conocer la gran mayoría de los problemas de salud existentes, con el objeto de diagnosticarlos $y$ tratarlos en forma adecuada ${ }^{1,4}$. Sin embargo, en nuestra realidad, el MG no puede resolver en profundidad los problemas que presentan las afecciones más complejas o de baja incidencia y difícil reconocimiento clínico. Requiere, entonces, la colaboración del médico especialista (ME), sito en el Consultorio de Especialidades del Hospital base de la Red asistencial, la que se realiza a través de referencias (interconsultas). En la práctica, se reconoce que éstas se solicitan con demasiada frecuencia y en forma injustificada, porque revelan inconsistencias de diagnóstico y manejo clínico. Por ello, se ha acusado a los MG de la APS de fallas en su capacidad de resolución clínica y terapéutica.

La capacidad resolutiva del médico, sea MG o ME, depende de la calidad y efectividad de su acción científico-técnica. Ella es la dimensión central necesaria para resolver los problemas de salud que enfrentan ${ }^{5}$. A la vez es la menos valorada, por las dificultades que tiene el análisis de su rendimiento clínico-sanitario y la apreciación de su dimensión humana. En nuestro medio se ha especulado mucho respecto a la escasa "resolutividad" de los MG, pero no existen en la literatura nacional datos concretos al respecto y, más aún, los que aparecen son contradictorios. En efecto, informes del Ministerio de Salud la estimaron en $86 \%$ entre los años $1994-2002^{6}$, en tanto que otros estudios la sitúan en cifras inferiores. Así, Saldías y cols, al evaluar la sensibilidad y especificidad del juicio clínico en pacientes con neumonía de la comunidad, calificaron la calidad resolutiva del Médico Internista en $83 \%$ versus $47 \%$ del $\mathrm{MG}^{7}$. Otro estudio reciente de la Pantoja y cols, basado en un análisis retrospectivo de las historias clínicas en más de 2.000 pacientes atendidos en la APS, comunicó 68\% de "resolutividad", incluidas las interconsultas correctamente derivadas ${ }^{8}$. Además, dicho estudio comprobó que los MG tenían tasas de derivación significativamente mayores que los Médicos de Familia, que son considerados especialistas 9 .

Por otro lado, se reconoce que un indicador importante de la calidad de la acción asistencial de la APS es la frecuencia y aproximación diagnóstica de las interconsultas al nivel secundario. En un estudio en que participó el autor, la hipótesis diagnóstica de las referencias a Cardiología desde los consultorios de APS fue considerada adecuada en $62 \%$ e incorrecta en $38 \%$ restante ${ }^{10}$ y en el estudio de Pantoja y cols, $68 \%$ del total de interconsultas a la atención secundaria había sido solicitado correctamente.

Para mejorar la capacidad de resolución clínica de la APS se ha pensado en la incorporación de especialistas básicos, en particular Internistas y Pediatras, a la atención de consultorios primarios, especialmente en aquellos con áreas comunitarias extensas y gran número de habitantes. El autor ha sido uno de los propiciadores de esa idea ${ }^{11}, y$ sin planificar ninguna acción, involuntariamente fue comisionado para realizar acción docente de alumnos de Medicina de $4^{\circ}$ año en un consultorio capitalino de APS. Allí, pudo comprobar que un ME con experiencia profesional podía alcanzar una resolutividad en Medicina General de Adultos de $80 \%$ y una frecuencia de petición de Interconsultas al nivel secundario del $23 \%$. Evidentemente estos datos deben ser considerados como referenciales, sin valor científico.

En dirección similar apunta el Programa de formación de especialistas básicos, iniciado en el año 2008 por Ipinza y cols ${ }^{12}$, que en un período de estudios de 6 años, formará médicos en los dos niveles de atención, primario y secundario, en forma alternada.

Creemos que el aspecto crucial del problema de la resolutividad clínica radica en establecer la profundidad y extensión de los conocimientos médicos, tanto de MG como de ME. Los especialistas, además de limitar el área de conocimiento y experticia, manejan tecnologías de apoyo diagnóstico y terapéutico, y además se apoyan en muchos años de experiencia, características que evidentemente no poseen los MG. Reconocemos que para muchos autores no existirían razones válidas para llevar especialistas a la APS para asumir roles que no les corresponden como tales. Sin embargo, frente a 
la baja resolutividad clínica exhibida por la APS, parece conveniente volver a discutir el problema. Además, será necesario evaluar el resultado de la formación mixta de especialistas básicos en ambos niveles de atención, primario y secundario, no sólo en cuanto a su capacitación personal sino también en su rendimiento profesional en el Sistema de Atención de la red de Salud del país.

Dr. Oscar Román A. Profesor de Medicina, Universidad de Chile.

\section{Referencias}

1. Zurro AM, Cano Pérez J F. Atención primaria de salud. $4^{\text {a }}$ Ed. 1999. Harcourt Brace. Madrid España.

2. Montoya C. Atención Primaria de Salud. Alma Ata otra vez y la experiencia de Chile. Cuad Med Soc (Chile) 2008; 48: 147-54.

3. Organización Mundial de la Salud. La atención primaria de salud más necesaria que nunca. Informe sobre la salud en el mundo 2008.

4- Armas Merino R. La medicina general, una realidad necesaria. V. Editorial Informativo Soc Méd Santiago. 1995.

5. Otero-Puime A, Hernández S, Marquet Palomer R. Mejora de la calidad de la atención primaria. En "Atención Primaria” Zurro y Cano Ed. 4ºd. Harcourt Brace Madrid 1995, pags 300-417.

6. DEIS. Ministerio de salud. Depto. de Atención Primaria-.
Resolutividad en Atención Primaria. Informe 2003.

7. Saldías F, Cabrera D, De Solminihac I, Hernández P, Gederlini A, Díaz F. Valor predictivo de la historia clínica y examen físico en el diagnóstico de neumonía del adulto adquirida en la comunidad. Rev Med Chile 2007; 135: 143-52.

8. Mercado R, Pantoja T, González C. Caracterización y análisis del perfil de derivaciones de un Centro de Salud familiar al nivel secundario. Monografía. Pontificia Universidad Católica de Chile, abril 2010.

9. Bass C. El médico general y de familia en el sistema de salud chileno-Visión de la Agrupación de Médicos de APS. 2009.

10. Román O, Meza N, Bahamonde A, Pino C, Plana C, Muñoz C. Evaluación de la calidad de las Interconsultas enviadas por la Atención Primaria a la especialidad de cardiología en el Servicio de Salud M. Central. Informe SSMC. 1999.

11. Román O.APS en manos de especialistas ¿una paradoja nacional?. Informe Minsal 2003.

12. Ipinza M. El modelo de atención integral de salud, base doctrinaria del programa de formación de médicos especialistas básicos para la atención primaria de salud. Cuad Med Soc (Chile) 2010; 50: 132-42.

Correspondencia a:

Dr. Oscar Román A.

Huelén 154. Depto. 2, Providencia. Santiago de Chile.

E.mail or.alemany@gmail.com 